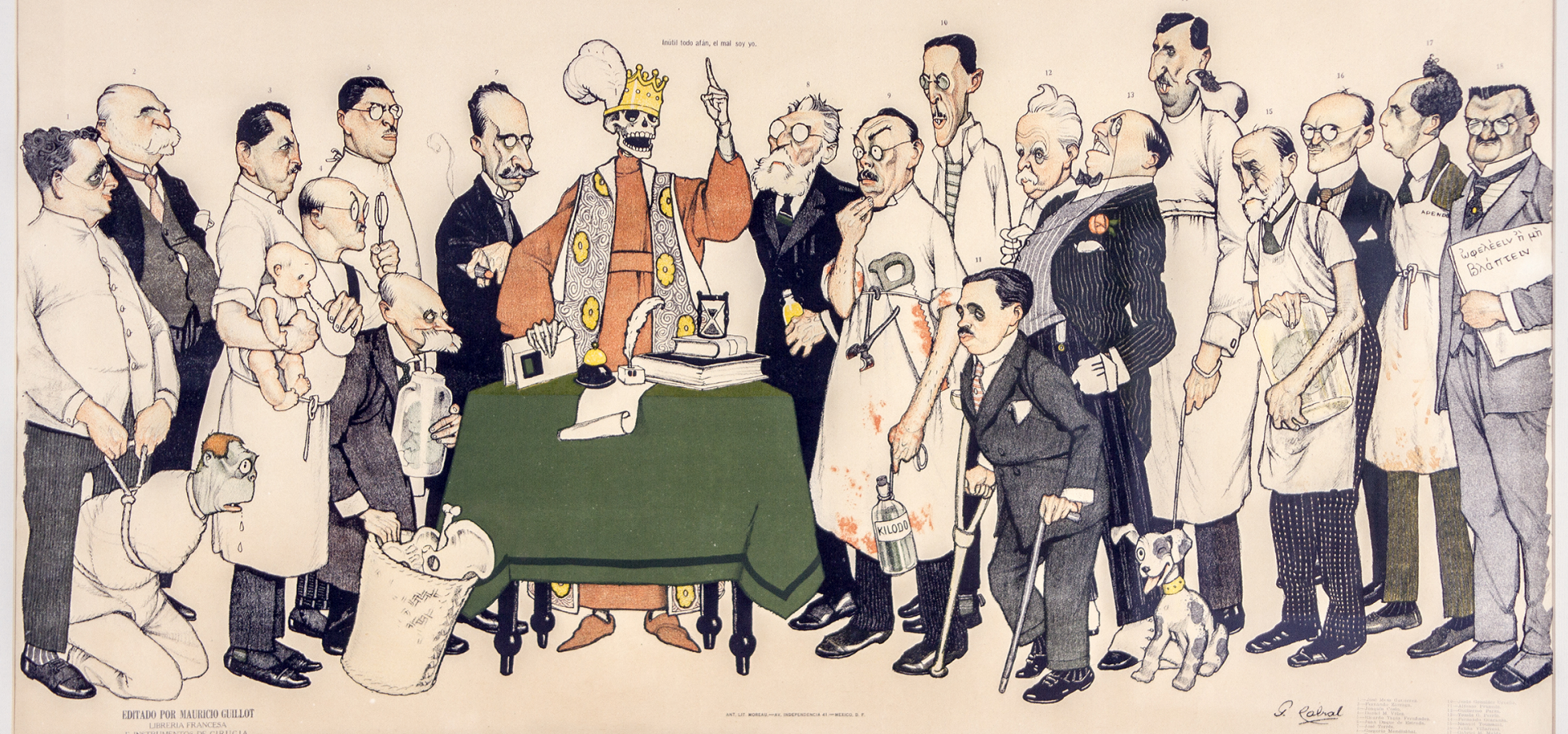

Los médicos. Autor: Ernesto García Cabral. Compartida por Henoc de Santiago Vulché, director de El Museo del Estanquillo, www.museodelestanquillo.cdmx.gob.mx/

\title{
Eronesto García Cabral y el círculo de médicos cercanos a Isaac Ochoterena
}

\section{Alejandro Hernández Daniel}

Instituto Estatal de Educación para Adultos Puebla, C. Z. 01 ludagsp@gmail.com

orcid.org/0000-0001-6988-3647
Miguel Ángel Rodríguez Cortés

Universidad Nacional Autónoma de México mifiguefel@gmail.com

orcid.org/0000-0001-5628-2236

Recibido: 27 de julio de 2020

Aceptado: 5 de septiembre de 2020

\section{Resumen}

Las imágenes como las caricaturas y retratos ofrecen una guía que nos permite vislumbrar el poder de persuasión y estética que tienen las representaciones visuales en la vida cotidiana incluyendo la ciencia y su historia. En este artículo se presenta la caricatura denominada Los médicos realizada por Ernesto García Cabral uno de los más importantes caricaturistas de México haciendo especial énfasis en los personajes de la medicina relacionados con Isaac Ochoterena y la polémica con Alfonso L. Herrera durante la temprana historia de la biología nacional. A través de esta imagen arte, historia y ciencia se unen para ofrecer un momento de reflexión.

Palabras clave: Iconografía, historia de la ciencia, historia de la biología

\section{Abstract}

Images such as caricatures and portraits offer a guide that allows us to perceive the power of persuasion and aesthetics that visual representations have in everyday life including science and its history. This article presents the caricature called "The medical practitioners" made by Ernesto García Cabral one of the most important cartoonists in Mexico, with special emphasis on the characters of mexican medicine related to Issac Ochoterena and the controversy with Alfonso L. Herrera during the early history of biology in Mexico. Through this image, art, history and science come together to offer a moment of reflection.

Key words: Iconography, history of science, history of biology 


\section{La caricatura y el retrato: su potencial uso en la historia de la ciencia}

A menudo se utilizan las imágenes en artículos, libros y revistas científicas para ilustrar los fenómenos que se mencionan en los textos, sin referirse al análisis de las imágenes en sí mismas, es decir, sin analizar estructuras de pensamiento o la representación de una determinada época, lo que sí han hecho pocos especialistas en historia de la ciencia, como Martin Rudwick, Janet Browne, Elías Trabulse y Erica Torrens Rojas. Aunque los textos y los testimonios orales ofrecen importantes pistas discursivas e históricas, las imágenes son también una importante fuente de documentación. Las pinturas, estatuas, caricaturas, dibujos, retratos y estampas "permiten compartir experiencias y conocimientos no verbales", como lo señala el historiador inglés Peter Burke (2005).

Dentro de las caricaturas y sátiras, el retrato es un género artístico particularmente difícil en la medida en la que exige precisión y fidelidad, los buenos caricaturistas al exagerar ciertos rasgos de los personajes resaltan su personalidad y ponen en evidencia aquello que los hace únicos. Los humoristas gráficos, además, pueden representar a las comunidades científicas e incluso a los grupos de poder, dejando así constancia de la realidad social, económica, política y cultural de una época determinada (Borregales, 2017). Las poses, los gestos y objetos representados junto a ellos siguen un esquema y a menudo están cargados de un significado simbólico. Tienen la finalidad de presentar al modelo de una forma determinada, por lo general favorable, aunque no debemos descartar la posibilidad de las propuestas satíricas. La aparición de accesorios pueden ser considerados "propiedades" del sujeto, es decir objetos simbólicos que hacen referencia a papeles sociales específicos.

Sin embargo, como todo documento histórico, se debe tener cuidado en tener siempre en cuenta la época y lugar en que fueron realizadas las imágenes para poder vislumbrar el contexto e interpretar correctamente el mensaje que emiten, ya que puede ser menos realista de lo que parece y más que reflejar la realidad social, distorsionarla. Por esta razón, los historiadores de la ciencia deben tener en cuenta la diversidad de las intenciones de los pintores o artistas para no cometer equivocaciones en su interpretación.

Este artículo es otro pequeño esfuerzo para contribuir en la valorización de los documentos visuales como las caricaturas, dibujos, fotografías o retratos en la historia de la ciencia en México.

\section{Ernesto García Cabral: su vuelta en escena después del olvido}

Nacido en Huatusco, Veracruz en 1890, Ernesto García Cabral alias "El Chango Cabral" fue uno de los dibujantes más destacados de la primera mitad del siglo XX en México. A lo largo de seis décadas produjo una vasta obra que ilustró una gran cantidad de libros, crónicas gráficas, cortinillas y carteles, muchos de ellos para el cine mexicano. Sus imágenes además de obras de arte; son también testimonios históricos. El conjunto de sus caricaturas conforma una crónica visual de un periodo clave de México y muchos de sus monos registran momentos fundamentales de la centuria pasada, entre ellos el retrato de

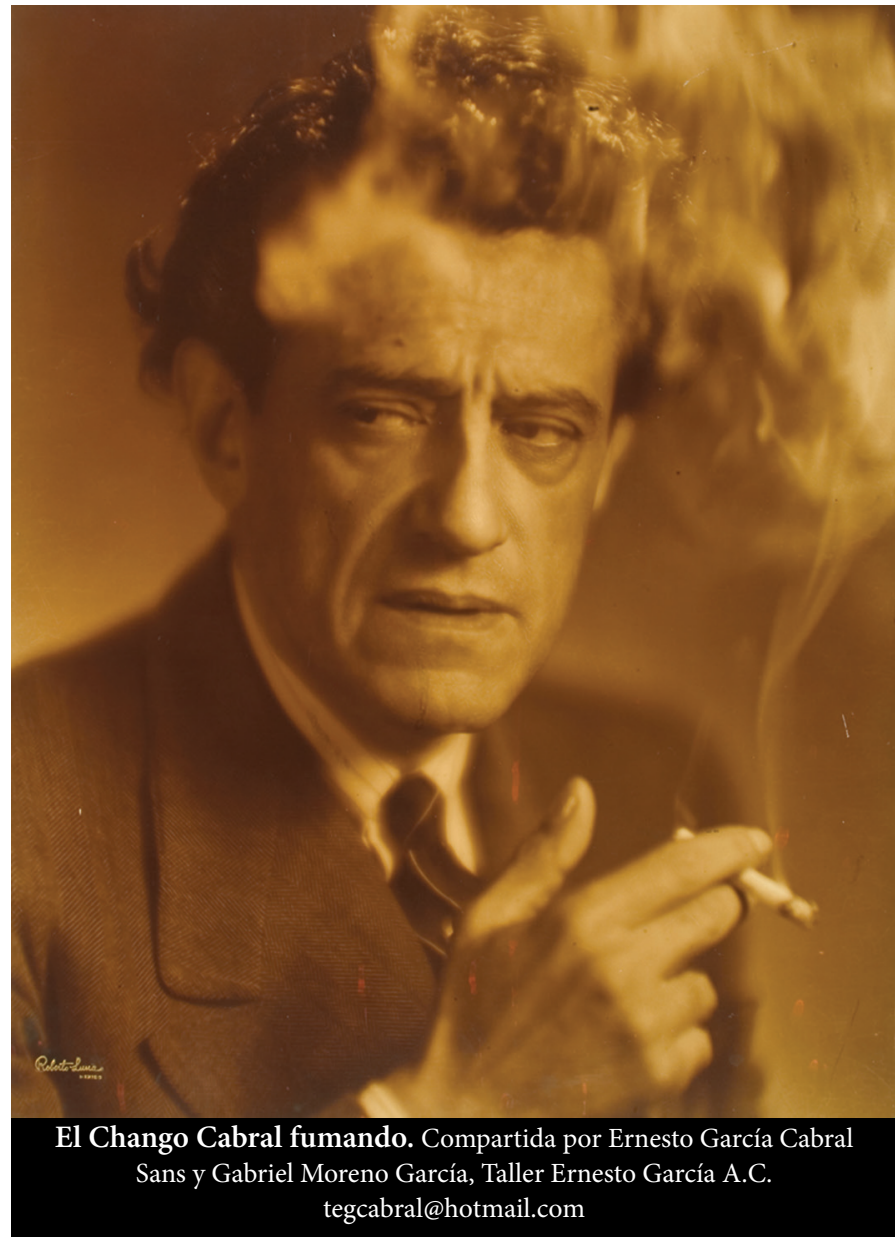

personalidades del ámbito científico nacional e internacional. Fue amigo de personajes como Diego Rivera, David Alfaro Siqueiros, Roberto Montenegro, Miguel Covarrubias, José Juan Tablada, María Félix, Germán Valdés Tin-Tan, Agustín Lara, Mario Moreno, Cantinflas y Pedro Vargas, estos tres últimos incluso fueron invitados a una fiesta de cumpleaños de El Chango. Su trabajo fue elogiado y galardonado de manera importante, entre ellos cabe mencionar el Premio Nacional de Artes Plásticas de México y el Premio Mergenthaler, concedido por la Sociedad Interamericana de Prensa.

No obstante, su obra fue olvidada tras su fallecimiento, acontecido en 1968, y durante décadas no se hizo una sola exposición importante de su trabajo. Dibujos y acuarelas permanecieron prácticamente ausentes de las salas de exposición de arte contemporáneo y hasta de los acervos de los museos más importantes de México. El público de pie durante muchos años rara vez pudo admirar una obra original y menos ver reunida una parte significativa de sus dibujos.

En el año 2005 un equipo de curadores que contó con el beneplácito del escritor Carlos Monsiváis y encabezado por Gloria Maldonado Ansó y Horacio Muñoz Alarcón, junto a la viuda del artista Lalis Sans y de sus hijos Ernesto, Vicente y Eduardo inició una labor de rescate sistemático del acervo de Cabral mediante la investigación y presentación de exposiciones en distintos lugares del país, como el Festival Internacional Cervantino. En 2012 el equipo logró que la Organización de las Naciones Unidas para la Educación, la Ciencia y la Cultura (UNESCO) le otorgara al archivo de Ernesto García Cabral el reconocimiento Memoria del Mundo México (Barajas, 2016). 
Su obra actualmente poco a poco ha sido objeto de análisis, revalorización cultural e investigaciones recientes, tales como la realizada por el caricaturista y monero Rafael Barajas Durán, mejor conocido como "El Fisgón”, curador y también coleccionista de la obra de García Cabral, quien recientemente presentó su libro El linchamiento gráfico de Francisco I. Madero. En este libro aborda una investigación histórica de la caricatura mexicana entre la que se encuentran los dibujos de "El Chango", provenientes de revistas como Frivolidades, La Risa, y Multicolor, que adquieren un nuevo significado discursivo gráfico dentro de temas tan profundos de la historia mexicana como lo fue La Decena Trágica, a través del rastreo de los personajes involucrados en los golpes mediáticos orquestados por los dueños de las revistas en las que alguna vez trabajó García Cabral, aunque sin llegar a definirse él mismo de forma concreta por alguna ideología, tal como lo expresó alguna una vez Carlos Monsiváis.

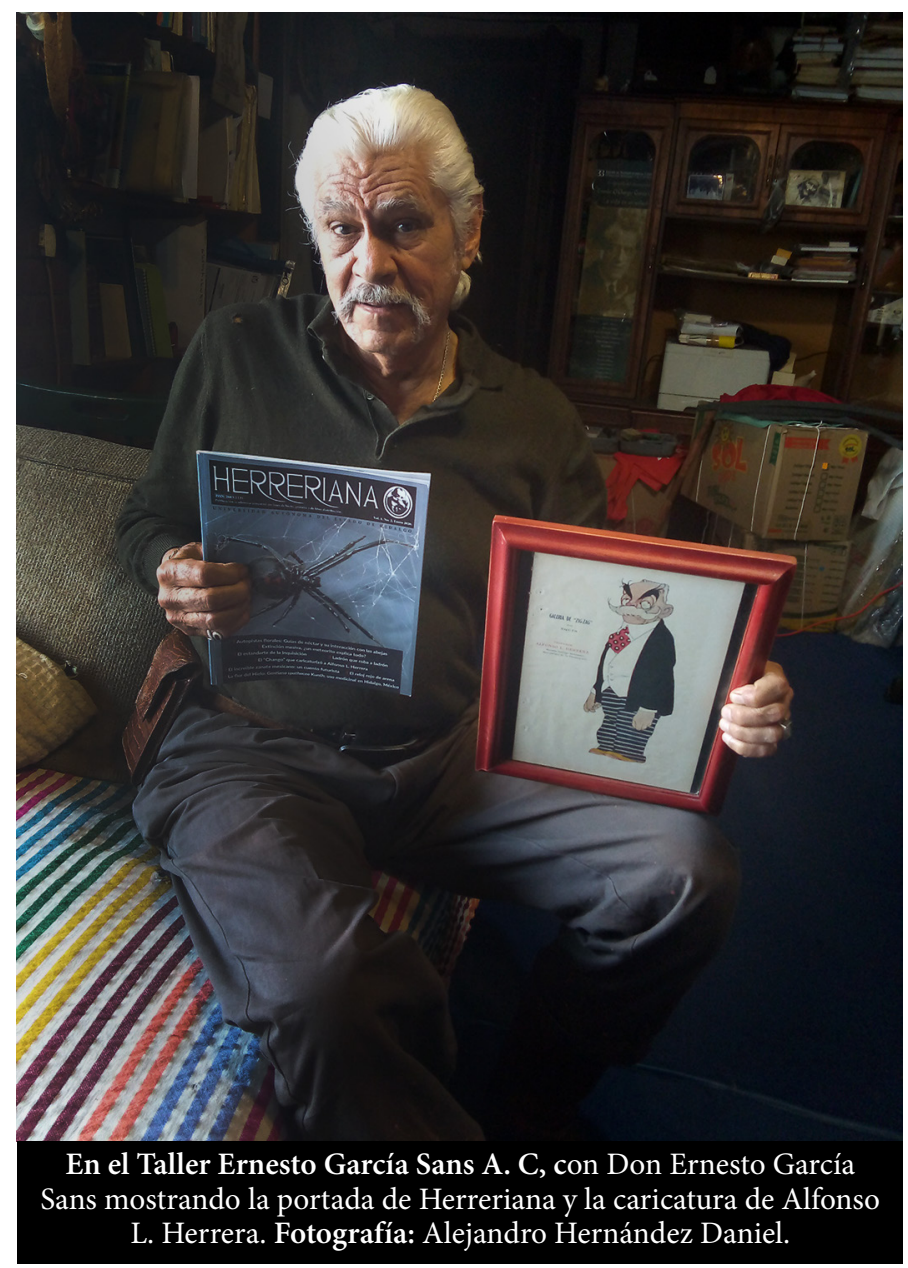

\section{El changuito, revista Herreriana y dos primates tomando café huatuxqueño}

El 17 de enero del presente año los autores realizaron una visita al Taller Ernesto García A. C. en la Ciudad de México siendo recibidos cordialmente por su director Ernesto García Sans mejor conocido como "El Changuito" hijo del caricaturista, quien ofreció una extensa charla y narró anécdotas de su padre, acompañadas de un excelente café proveniente de Huatusco.

Después de mostrarle la caricatura de Alfonso L. Herrera que su padre dibujó para la revista Zig-Zag en 1920, y de la cual no tenía conocimiento -ni del dibujo ni del científico-, reveló que su padre solía firmar como "X" en Zig-Zag, debido a que tenía comprometida su firma en otra publicación de aquel tiempo, por lo que no podía usar su nombre o apellidos. También se le compartió el artículo de la revista Herreriana en que salió publicado el artículo dedicado al dibujo de Alfonso L. Herrera (Hernández-Daniel, 2020) y finalmente se le mostró un ejemplar del libro Plasmogenia escrito por Don Alfonso en 1924.

Posteriormente se tuvo la oportunidad de que mostrara una pequeña selección de los más de 30,000 documentos que se resguardan en el archivo del taller, muchos de ellos aún sin ser estudiados a profundidad, situación que lamentó nuestro anfitrión, puesto que no se explica que aún no exista el suficiente interés para asegurarle un lugar a Cabral en la historia del arte mexicano contemporáneo. Comentó que su voluntad y deseo es que la totalidad de la obra de su padre permanezca bajo el resguardo de alguna institución universitaria, de educación o museo público, pero que de no llegar alguna oferta nacional adecuada, probablemente deba venderla en el extranjero.

Finalmente se le preguntó si existía una clasificación de personajes representativos de la ciencia, pregunta a la que de manera directa respondió explicando que hasta ahora solo habían identificado muy pocos dibujos al respecto. Uno de los que mostró es la caricatura objeto del presente artículo. Puntualizó que muchos de los personajes que aparecen en ella fueron amigos de "El Chango", pues trabajó como ilustrador de las publicaciones mensuales de la Gacetilla Bayer, perteneciente a la Casa Bayer S. A., entre 1931 y 1964. Algunos de los personajes que aparecen en la caricatura son tan ilustres, que sus nombres continúan siendo los nombres de las calles de la colonia Doctores en la Ciudad de México.

\section{Los médicos de Cabral y la sutil sátira de la práctica médica}

Los nombres de la imagen Los Médicos no eran legibles a simple vista, por lo que se obtuvo una imagen digitalizada, gracias al Licenciado Henóc de Santiago Dulché, Director de El Museo del Estanquillo, ubicado en el Centro Histórico de la Ciudad de México, a donde pertenece el original de la obra. Su nombre completo es Los médicos mexicanos en caricatura y se trata de una litografía en color, una sátira que tal vez le fue encargada a Cabral como parte de la publicidad para un negocio de venta de libros y materiales quirúrgicos, en 1921.

Se observan varios personajes con diferentes especialidades médicas que los distinguen entre sí, ya sea por medio de la vestimenta o de algún aditamento. Todos se encuentran en torno a la figura de un esqueleto humano ataviado con túnicas coloridas y una corona con una pluma adjunta que simboliza a La Muerte, único integrante de la composición que simula emitir o apuntar una frase "Inútil todo afán, el mal soy yo".

Una vez adquirida la digitalización, los nombres que aparecen en sentido de izquierda a derecha son: (1) José Mesa Gutiérrez, (2) Fernando Zárraga, (3) Joaquín Cosío, (4) Daniel M. Vélez, (5) Ricardo Tapia Fernández, (6) Juan Duque de Estrada, (7) José Terrés, (8) Gregorio Mendizábal, (9) Regino González, (10) Jesús González Urueña, (11) Alfonso Pruneda, (12) Guillermo Parra, (13) Tomás Gutiérrez Perrín, (14) Fernando Ocaranza, (15) Manuel Toussaint, (16) Julián Villarreal, (17) Gabriel M. Malda y (18) Francisco C. Canale. 


\section{El gremio médico e Isaac Ochoterena}

Isaac Ochoterena Mendieta fue un profesor rural originario de Atlixco en el estado de Puebla que cultivó de manera autodidacta su interés por la historia natural y la fisiología. Su intención era estudiar medicina, aunque nunca lo pudo concretar. Publicó diferentes trabajos al respecto y ocupó varios puestos en diferentes estados, hasta que al hacerse conocido del ingeniero Pastor Rouaix, hombre de confianza de Venustiano Carranza y encargado de la Secretaría de Fomento, Colonización e Industria, lo recomienda con Alfonso Luis Herrera López para ocupar un lugar en la Dirección de Estudios Biológicos.

La Dirección de Estudios Biológicos se inauguró el 2 de Octubre de 1915 y fue una institución de investigación dirigida por Alfonso Luis Herrera López, fundador de la cátedra de biología en 1902 en la Escuela Normal para Profesores. El edificio se ubicó en la actual esquina convergente entre las calles de Balderas y Ayuntamiento, en la Ciudad de México. El edificio fue diseñado por su hermano Carlos Herrera López por encargo de su padre, el naturalista Alfonso Herrera Fernández, y que terminó por ser la sede del Instituto Médico Nacional, un centro dedicado al estudio de plantas y animales medicinales que existió entre 1888 y 1915. Su último director fue José Terrés, quien ocupa el número 7 de la caricatura. De acuerdo con Ismael Ledesma (2007), la desaparición del Instituto Médico Nacional y su sustitución y desplazamiento por la Dirección de Estudios Biológicos que impulsó Alfonso Luis Herrera López, se interpretó por parte de varios miembros de la comunidad médica como una afrenta directa e imperdonable a los intereses, simbolismo y poder por parte de alguien que no pertenecía al gremio médico.

Entre 1915 y 1916, poco tiempo después de que el Instituto Médico Nacional dio paso a la Dirección de Estudios Biológicos, Fernando Ocaranza Carmona (14), médico cirujano egresado de la Escuela Nacional de Medicina, fue nombrado profesor de la Sección de Fisiología Experimental en la Dirección de Estudios Biológicos, a pesar de que su intención original era aspirar a una materia de clínica. A pesar de carecer de los conocimientos adecuados en la materia, aceptó el cargo y empezó a realizar investigaciones sobre algunas constantes fisiológicas del cobayo y de los seres humanos y su aclimatación en el Valle de México (Calva-Cuadrilla y Mendoza-Hernández, 2006). Con esto la intención era continuar la propuesta que había sido iniciada por Herrera y por el también médico Daniel Vergara Lope Escobar, quien llegó a ser miembro y presidente de la Sociedad Científica Antonio Alzate en 1897 y director de la sección de Fisiología Experimental del Instituto Médico Nacional, tanto Herrera y Vergara Lope escribieron en 1899 el libro La vie sur les hauts plateaux. Influence de la pression barométrique sur la constitution et le development des êtres organisés, lo que les valió un premio por el prestigiado Instituto Smithsoniano sin embargo Ocaranza no siguió este camino optando por su acercamiento a la medicina.

Fernando Ocaranza coincide, conoce y mantiene amistad con los profesores Isaac Ochoterena, en ese entonces a cargo de la Sección de Biología Vegetal, y con Eliseo Ramírez Ulloa. De hecho, en 1916 Eliseo Ramírez ingresó a la Sociedad Científica Antonio Alzate a propuesta de Isaac Ochoterena, siendo presidente de la sociedad de aquel año el médico (4) Daniel María Vélez Cañizo (Rodríguez-Carmona, 2018) y en 1917, un año antes de que Ochotorena abandonara la Dirección de

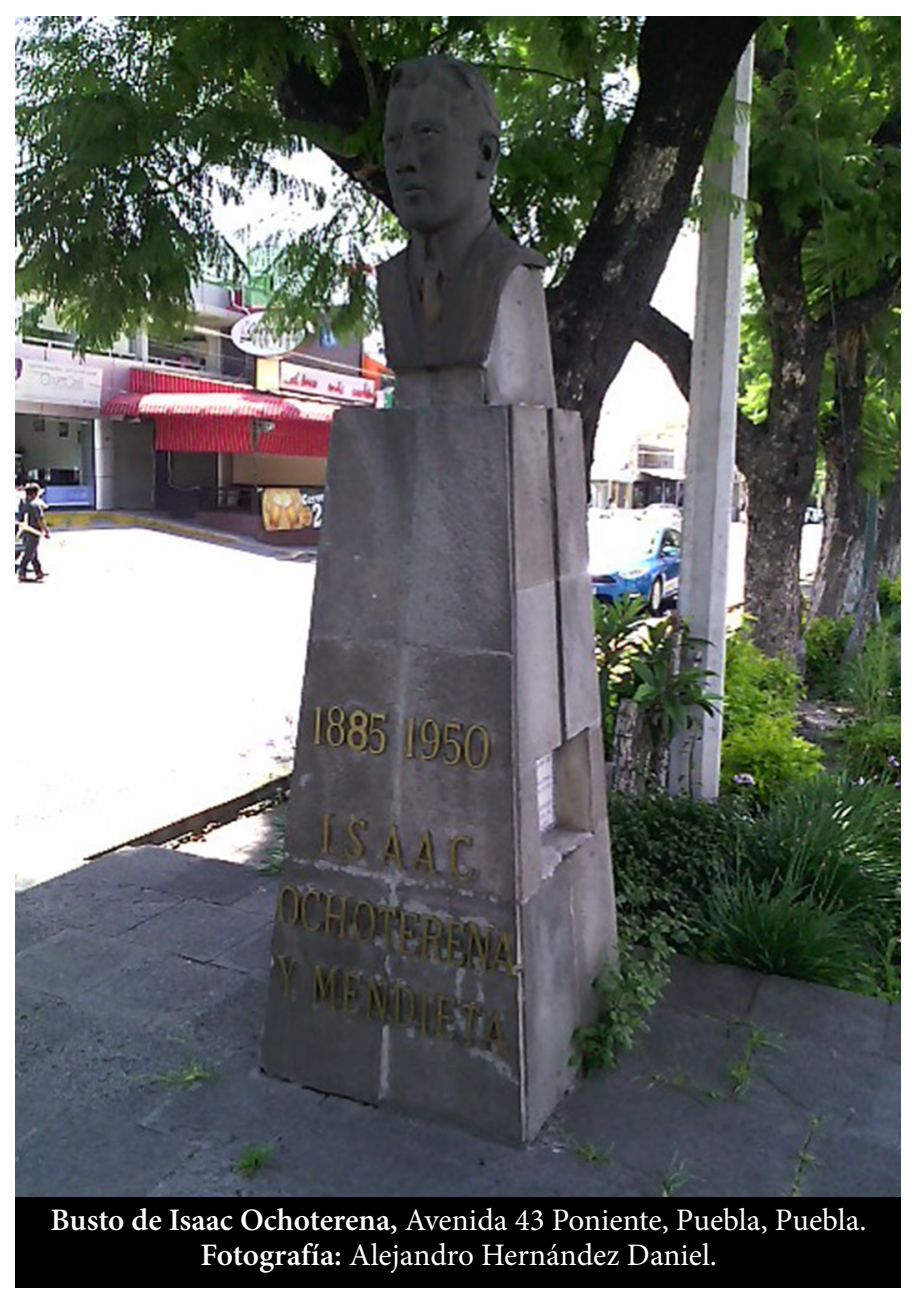

Estudios Biológicos, Eliseo Ramírez lo invitó a ser profesor de la Escuela Médico Militar. En esta institución convergieron nuevamente Ochoterena, Ocaranza y Ramírez Ulloa. Este trío de personajes con intereses clínicos conformarían de acuerdo con los investigadores Daniel Piñero Dalmau e Ismael Ledesma Mateos (Piñero-Dalmau y Ledesma-Mateos, 2016) un grupo constantemente crítico respecto a los objetivos de investigación de Alfonso L. Herrera, centrados en la explicación de los fenómenos de la vida, su origen y evolución fundamentos de la biología.

Es así que al poco tiempo de la salida de Ochoterena de la Dirección de Estudios Biológicos en 1918 él junto con Fernando Ocaranza y Eliseo Ramírez conforman la Sociedad Mexicana de Biología que surge como parte de un proyecto académicopolítico (Ledesma-Mateos, 2009) como consecuencia de su confrontación con Alfonso L. Herrera. A pesar de su nombre, esta nueva institución tenía una orientación hacia aspectos más próximos a lo médico que a lo biológico. Sus fundadores fueron Antonio F. Alonso, Francisco Castillo Nájera, Ernesto Cervera, José Joaquín Izquierdo, Jesús J. Mojarás, Fernando Ocaranza, Isaac Ochoterena, (12) Guillermo Parra, (13) Tomás Gutiérrez Perrín, (14) Alfonso Pruneda, y Eliseo Ramírez. El primer director de la Sociedad Mexicana de Biología fue Isaac Ochoterena en 1920, sucedido por Eliseo Ramírez, Ignacio González Guzmán y Fernando Ocaranza. Se creó asimismo, la Revista Mexicana de Biología con una inclinación hacia los temas de medicina que fue un espacio de contrapeso al Boletín de la Dirección de Estudios Biológicos, órgano de difusión de Alfonso L. Herrera. 
En aquel año de 1921 en que Ernesto García Cabral retrató a los médicos, Daniel M. Vélez médico y miembro de la Sociedad Científica Antonio Alzate dictaba la cátedra de oftalmología en la Facultad de Altos Estudios; José Terrés se había retirado después de 25 años de tener la plaza de Patología Médica en el Hospital de San Andrés; (10) Jesús González Urueña impartía la cátedra de dermatología en la Facultad de Altos Estudios donde colaboró con Isaac Ochoterena, siendo este último nombrado en aquel entonces jefe del Departamento de Biología de la Escuela Nacional Preparatoria, desde entonces la amistad entre ambos duraría toda su vida (Ledesma-Mateos, 2007); Alfonso Pruneda médico miembro y posterior presidente de la Sociedad Científica Antonio Alzate era Rector de la Universidad Popular Mexicana; Guillermo Parra asumía el puesto de Director de la Escuela Nacional de Medicina; Tomás Gutiérrez Perrín, médico español, compañero y amigo de Santiago Ramón y Cajal y miembro de varias sociedades médicas y científicas, impartía la materia de anatomía en la Escuela Médico Militar y Fernando Ocaranza, miembro del Consejo Superior de Salubridad, impartía clases de fisiología en la Escuela Médico Militar.

De 1924 a 1925 sucedieron cambios dramáticos en cuanto a las instituciones que impartían biología en el país: se anunció la desaparición de la carrera de Profesor Académico en Ciencias Naturales en la Facultad de Altos Estudios donde Alfonso L. Herrera y Enrique Beltrán, uno de sus discípulos, prestaban sus servicios y se integró a la Facultad de Filosofía y Letras. En ese momento Isaac Ochoterena desplaza como profesor a Alfonso L. Herrera en la cátedra de Zoología dejándolo fuera de cualquier actividad institucional universitaria. Fue también cuando Fernando Ocaranza escribió en el prólogo de uno de sus libros: "He procurado colocarme constantemente dentro de la

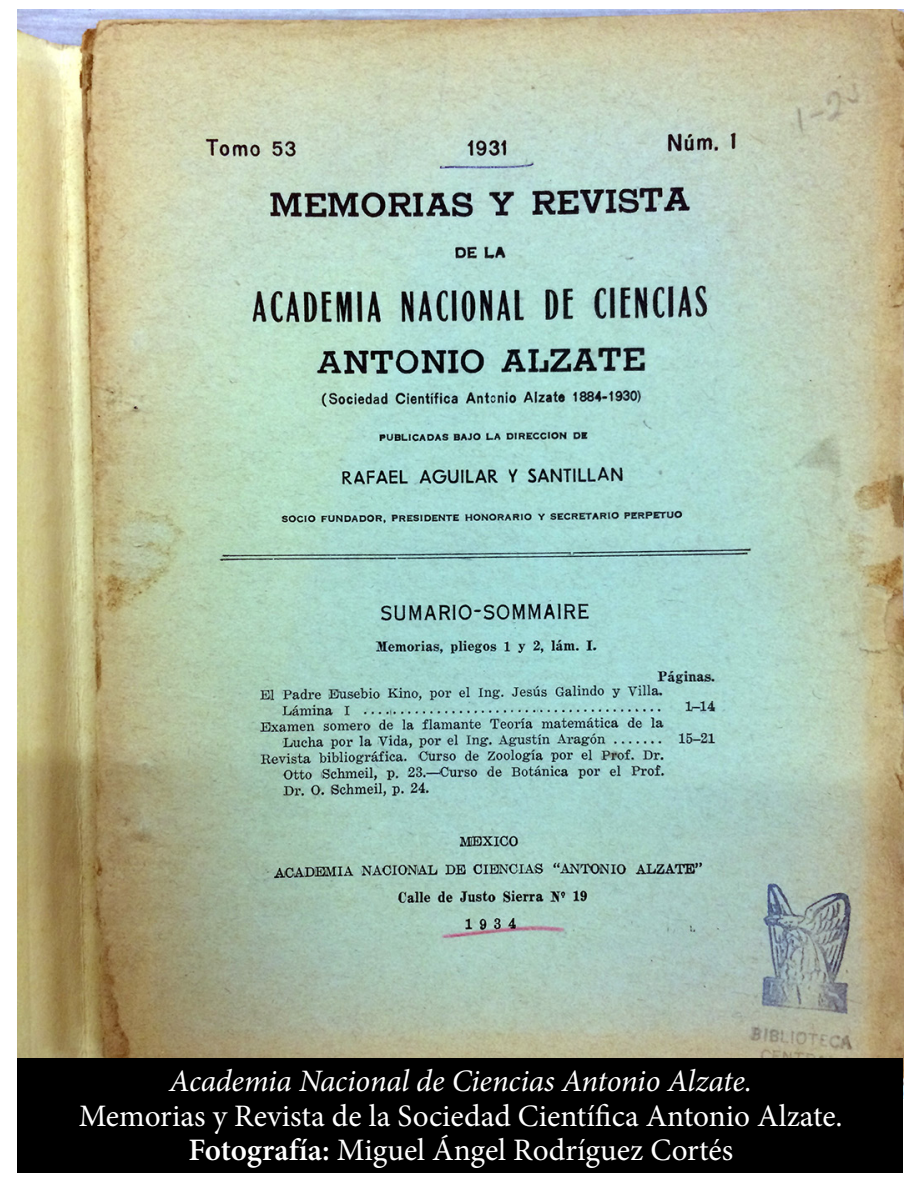

disciplina determinista, apartándome cuanto me ha sido posible de la influencia inmediata o directa de darwinianos y neodarwinianos, de lamarckianos y neolamarckianos y de weismanianos y neoweismanianos" (Ocaranza, 1925).

Que es una antesala de la proscripción de la enseñanza de la evolución y por lo tanto de las enseñanzas de Alfonso L. Herrera en México concretada cuando en 1929 Ocaranza propone al Consejo Universitario de la ahora Universidad Nacional Autónoma de México la terna para ocupar la dirección del nuevo Instituto de Biología y también se plantea un nuevo programa para el instituto donde de manera explícita se menciona:

"No se pide por ahora, por no considerarse necesario en el momento actual una sección de biología general que investigue problemas tan arduos...como son el origen de la vida y el concepto que de ella se pueda tener" (Ledesma, 2007).

\section{Una breve interpretación}

La litografía de Ernesto García Cabral no formaba parte de una revista sino que fue un encargo de publicidad dirigido a un público selecto, muestra de esto es que en la parte inferior izquierda puede leerse: "Librería francesa e instrumentos quirúrgicos". En esa casa comercial se vendían objetos que estaban al alcance de unos pocos círculos sociales que tenían cierta capacidad económica. Tal vez se tenga que considerar que el dibujo, a pesar de ser una sátira y una velada crítica por parte de Cabral concerniente a la práctica médica, no necesariamente pudo haberse notado por quien encargó la obra puesto que tiene la característica de destacar a varias "eminencias de la comunidad médica”, tal como en la actualidad las agencias publicitarias imponen figuras reconocidas del deporte para anunciar marcas de bebidas con alto contenido en calórico.

En cuanto a la interpretación del mensaje de Cabral nos limitaremos a seguir ciertas convenciones iconográficas tomando en consideración la propuesta de la historiadora del arte Davinia Gómez Martín (Gómez-Martín, 2014) quien plantea que los elementos de la caricatura pueden interpretarse por ciertos simbolismos muy puntuales, ya que no hay que olvidar que a pesar de todo Ernesto García Cabral plasmaba muchos de estos elementos en sus obras, aunque siempre hay que dejar la puerta abierta a posteriores y más acertadas interpretaciones y lecturas con mayor fundamento.

El esqueleto humano representaría una metáfora de la muerte, pero en una forma que sugiere dinámica como intermediario entre la vida a la vez de representar cierta agresividad porque ataca y derriba, posee una corona y una pluma en la cabeza que sugieren nobleza y jerarquía y viste una túnica en la que se pueden apreciar flores que simbolizan lo efímero de la vida. Delante del esqueleto hay un reloj de arena que conceptualiza la sucesión de instantes que marcan el paso hacia lo inevitable de la muerte, también se ven libros y pergaminos que se expresan como vanitas, cuyo significado equivale a la vanidad del conocimiento, los placeres y en general a todo lo que tarde o temprano sucumbirá, pues el papel del que están hechos se desintegra pronto enviando un mensaje de humildad ante las propias limitaciones y la soberbia.

Para finalizar quisiéramos hacer remarcar que Ernesto García Cabral experimentó personalmente conflictos en los que las 
pérdidas de vidas humanas eran usuales, desde la Revolución mexicana, el enterarse en Europa sobre el asesinato de su benefactor Francisco I. Madero en la Decena Trágica, la invasión alemana en Francia durante la Primera Guerra Mundial y los constantes levantamientos armados cuando regresó a México.

\section{Agradecimientos}

Muy especiales agradecimientos a: Tonalli Hernández Saucedo, Francisca Daniel Durán, Ernesto García Sans y al Taller Ernesto García Cabral A. C., Henoc de Santiago Dulché Director del Museo de El Estanquillo, Horacio Muñoz Alarcón curador independiente de Ernesto García Cabral, Ismael Ledesma Mateos, Minerva Contreras Arroyo, Consuelo Cuevas Cardona, Andrés Pineda encargado del Archivo Histórico de la Academia Nacional de Medicina, Jorge Zacarias, Archivo Histórico de la Facultad de Medicina, Omar Escamilla Jefe del Acervo Histórico del Palacio de Minería, Óscar Daniel Áca, Ricardo E. Caicedo Rivas, Antonio Fernández Crispín, Ana Lucía Castillo Meza, Juan Héctor García Chávez, Javier Rolando Castrejón Acosta Subdirector de Bibliotecas del Distrito Federal y Coordinador de la Biblioteca Personal de Carlos Monsiváis, José Sarukhán Kérmez y Bernabé Daniel Durán.

\section{Referencias}

Barajas-Durán, R. 2016. El Universo Estético de Ernesto García Cabral. Asociación Cultural El Estanquillo A. C., México.

Burke, P. 2005. Visto y no visto. El uso de la imagen como documento histórico. Biblioteca de Bolsillo, Madrid.

Borregales, Y. 2017. Importancia de la caricatura como fuente de conocimiento histórico. Centro de Investigaciones Históricas Maio Briceño Iragorry, XXXV (68): 111-128.

Calva-Cuadrilla, E. y Mendoza-Hernández, S. E. 2006. Fernando Ocaranza Carmona. Coronel Médico Cirujano, Revista Sanidad Militar Mexicana, 60 (4): 284-285.

Gómez-Martín, D. 2014. Iconografía de la muerte en el arte occidental moderno. Tesis de grado en Historia del Arte, Madrid.

Hernández-Daniel, A. 2020. El Chango que caricaturizó a Alfonso L. Herrera. Herreriana, 1 (2): 6-10.

Ledesma-Mateos, I. 2007. De Balderas a la Casa del Lago. La institucionalización de la biología en México. Universidad Autónoma de la Ciudad de México, México.

Ledesma-Mateos, I. 2009. Biología, institución y profesión: centros y periferias. Educación y Cultura, México.

Ocaranza, F. 1925. Lecciones de biología general. Editorial Hispano Mexicana, México.

Piñero-Dalmau, D. y Ledesma-Mateos, I. 2016. Mesa redonda: Historia y Filosofía de la biología en México. Primer Congreso Estudiantil de Biología. Instituto Politécnico Nacional, Facultad de Ciencias Biológicas, 9,10 y 11 de Noviembre: https://www.youtube.com/ watch?v=kKiAjvOqkv4

Rodríguez-Carmona, M. A. 2018. Trascendencia de la Sociedad Científica Antonio Alzate del siglo XIX al XX para el biólogo. Tesis para obtener el título de biólogo. Facultad de Estudios Superiores Iztacala-Universidad Nacional Autónoma de México.
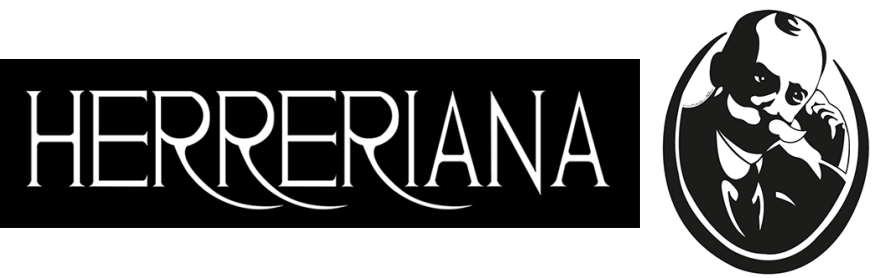